DOI 10.37882/2223-2974.2021.02.02

\title{
СОЦИАЛЬНО ПРАВОВОЕ ОБОСНОВАНИЕ УГОЛОВНОЙ ОТВЕТСТВЕННОСТИ ЗА ПОРЧУ ЗЕМЛИ В РОССИЙСКОЙ ФЕДЕРАЦИИ
}

\section{SOCIAL AND LEGAL JUSTIFICATION OF CRIMINAL LIABILITY FOR LAND DAMAGE IN THE RUSSIAN FEDERATION A. Agafonov}

Summary: In the article proposed by the author, from certain doctrinal legal and criminological positions, a formal attempt is made to identify and analyze the determinants of the subsequent criminalization of socially negative and socially dangerous encroachments on the biological quality and content of soil cover in the Russian Federation.

In the course of this analysis, the author analyzed the works and works of quite well-known, both Soviet and Russian legal scholars on the present doctrinal and legal problems.

At the same time, we have found that a significant part of them, as the main criteria for criminalizing socially negative and dangerous acts, distinguish precisely the social danger, identifying and fixing in the future in their works precisely the signs of the latter, which in turn either directly characterize it, or only indirectly cause this kind of danger.

To substantiate and confirm his conclusions, the author also used the statistical data available to him from various law enforcement agencies of the modern Russian Federation.

The article concludes that there is a slow but clear and obvious increase in such crimes as land damage.

Keywords: land damage, criminological analysis, criminal act, hygienic standards, sanitary and chemical indicators, microbiological indicators, environmental situation, socially determined negative phenomenon, public danger, criminalization, crime, crime, criminal law norm, statistical indicators.

\author{
Агафонов Александр Владимирович \\ К.ю.н., ФГБОУ «Красноярский государственный \\ аграрный университет», \\ info@kgau.krasedu.ru
}

Аннотация: В предложенной автором статье, с определенных доктринально правовых и криминологических позиций предпринимается формальная попытка выявить и провести анализ детерминант последующей криминализации социально негативных и общественно опасных посягательств на биологическое качество и содержание почвенного покрова в Российской Федерации.

В ходе осуществления настоящего анализа автором были проанализированы труды и работы довольно известных, причем как советских, так и российских ученых правоведов по настоящей доктринально правовой проблематике.

При этом нами было выявлено, что существенная их часть качестве основных критериев криминализации социально негативных и опасных деяний выделяют именно общественную опасность, выявляя и закрепляя в дальнейшем в своих трудах именно признаки последней, которые в свою очередь, либо напрямую характеризуют ее, либо всего лишь косвенно обуславливают подобного рода опасность.

Для обоснования и подтверждения своих выводов автором были использованы и доступные ему статистические данные различных правоохранительных ведомств современной Российской Федерации.

В статье сделан вывод о медленном, но явном и очевидном росте таких преступлений, как порча земли.

Ключевые слова: порча земли, криминологический анализ, криминальное деяние, гигиенические нормативы, санитарно-химические показатели, микробиологические показатели, экологическая ситуация, социально обусловленное негативное явление, общественная опасность, криминализация, преступление, преступность, уголовно правовая норма, статистические показатели.

ления жизнедеятельности современного российского общества [15].

Так, например, по мнению И.И. Карпеца «... социальный характер преступности определяется тем, что она является отражением (результатом) возникающих и существующих в обществе противоречий между людьми в процессе производственных отношений, включая распределительные»[7], а узко социальная специализация норм уголовного права, как указывал еще ранее Г.А. Злобин, как раз и состоит в том, что они напрямую «... запрещают совершение тех или иных деяний (действий и бездействия) под страхом строгих мер государственного характера» [5]. 
Таким образом и это следует признать вполне социально оправданным, криминализация социально негативной деятельности в отношении почвенного покрова нашей страны ныне вполне социально оправдана, так как обусловлена ее весьма повышенной степенью общественной опасности. Признавать ее субъективным решением российского законодателя у нас нет ни каких оснований.

Подвергая последующей криминализации настоящие, причем явно общественно опасные деяния, российский законодатель, безусловно, вынужден принимать во внимание весьма существенное и довольно объемное количество весьма различных факторов, изначально составляющих предпосылки настоящего решения.

По нашему мнению, в этом случае, явно необходимо отметить и то весьма существенное обстоятельство, что в современной нам российской доктринально правовой литературе довольно подробно отражены весьма различные и порой прямо противоположные по своей амплитуде колебания, мнения по вопросам выявления критериев криминализации социально негативных и более того общественно опасных деяний.

При этом основная часть российских доктринальных работников в качестве социально значимой предпосылки последующей криминализации подобного рода деяний выдвигает именно общественную опасность.

Так, например, Г.А. Злобин прямо указывал на то, что именно общественную опасность совершенного деяния рассматривает российский законодатель в качестве весьма существенного основания для ее последующей криминализации [5].

Позицию последнего позднее фактически полностью поддержал и П.С. Тоболкин. Так, по его мнению, «...в области уголовного права основополагающей категорией, дающей общее освещение всех основных проблем теории советского уголовного права, обеспечивающей концептуальное единство уголовно-правовых знаний, является категория общественной опасности» [15].

В дальнейшем П.А. Фефелов постарался творчески развить основные положения теории предложенной Г.А. Злобина и П.С. Тоболкина и в свою очередь настаивал на том, что именно общественная опасность совершенного антиобщественного деяния выступает в дальнейшем в качестве единственного основания ее последующей криминализации и более того, по его мнению, сконструированная таким образом уголовно правовая норма должна изначально содержать в себе и все необходимые и достаточные условия для обеспечения наступления неотвратимости понесения виновным лицом уголовного наказания [16].
Иные российские авторы, формально логически развивая далее теоретическую конструкцию, предложенную в свое время П.А. Фефеловым, в свою очередь, по нашему мнению, попытались выявить при этом факторы, как изначально связанные, так и обусловленные последней.

К числу которых, по нашему мнению, следует отнести, в первую очередь, именно В.И. Курляндского, который в свое время не только выявлял, но и пытался подвергать научному анализу основания, учитываемые, по его мнению, советским законодателем при дифференциации им уголовно наказуемых деяний [9].

В дальнейшем его фактически полностью П.С. Дагель, который, в свою очередь, настаивал на том, что «... к числу важнейших факторов, определяющих объективную потребность общества в криминализации, относятся, прежде всего, общественная опасность деяния, степень распространенности этих деяний и невозможность успешной борьбы с ними менее репрессивными мерами» [2]

Третья группа российских доктринальных правоведов, явно предприняли формальную попытку несколько расширить систему общих оснований криминализации, считая в свою очередь, что их перечень явно не является исчерпывающим.

Так, например, по нашему мнению, к числу последних следует отнести и И.М. Гальперина. Последний постарался сформулировать целый комплекс задач, который должен решать российский законодатель при последующей криминализации общественно опасных деяний.

К числу которых настоящий российский исследователь относил не только необходимость изучения степени распространенности социально опасных деяний, но и выявление степени их типичности, с явным учетом исследования всех доступных последнему детерминантов их обуславливающих; определение и фиксацию социально значимых последствий этих деяний; определение всех возможных мер профилактического воздействия, причем осуществляемого как в отношении самих виновных лиц, так и в отношении деяний ими совершаемых; выявления наиболее сущностных социально опасных, причем как объективных, так и субъективных признаков состава анализируемых асоциальных деяний; реальность и возможность последующей криминализации и установление мер уголовной ответственности [1].

Четвертая группировка российских ученых, по нашему мнению, в основу установления уголовной ответственности за совершенные общественно опасные деяния, считает необходимым положить, именно степень распространенности последних, традиционно выявляе- 
мую при этом через их статистические показатели [17].

Таким образом, вполне логически обоснованной, по нашему мнению, представляется нам необходимость осуществить анализ всей системы предпосылок криминализации общественно опасных деяний.

Предварительно изучение и обобщение доступных нам статистических показателей и доктринально обусловленных мнений российских ученых позволяет нам, по нашему мнению, зафиксировать две основные группы настоящих предпосылок.

В качестве первой из которых, как мы это в свою очередь, считаем выступают основания криминализации, относящие к любому виду общественно опасного деяния. Это так называемые общие предпосылки. К ним следует, по нашему мнению, отнести:

- во-первых, факторы, подтверждающие и обуславливающие довольно высокую социальную опасность конкретно совершенного общественно опасного деяния;

- во-вторых, данные правовой статистики, характеризующие степень распространенность этого деяния.

Следующая группировка состоит, в свою очередь, из совокупности факторов, специфическое содержание которых характеризует именно анализируемое нами деяние. Налицо, так называемые - специальные факторы.

К числу последних, как мы считаем, следует отнести:

- продолжающийся в Российской Федерации кризис экономики;

- безусловно, имеющий место быть кризис в области норм современно морали и нравственности ее населения;

- постепенное, но явно неуклонное повышение общего количества всех экологических преступлений.

При этом, следует признать, перечень предложенных нами специальных факторов явно не страдает своей формальной ограниченностью. Вполне вероятно выявление и иных подобных подобного рода факторов. Последнее, как мы, в свою очередь, считаем, остается за нашими оппонентами.

Таким образом, все последующие авторские рассуждения и выводы будут построены именно на анализе предложенной нами системы.

В качестве основного фактора криминализации социально негативного посягательства на биологическую сублимацию почвенного покрова в нашей стране выступило, по нашему мнению, именно общественная опас- ность последнего.

В этом фактически нас поддерживал и ранее, довольно известный омский ученый - правоведе А.И. Марцев, согласно мнению которого именно «...общественная опасность первична по отношению к признаку формальной запрещенности преступления, а признак запрещенности, в свою очередь, вторичен по отношению к общественной опасности» [11].

При этом, общепризнанно, что общественная опасность преступления есть некое формализованное свойство и проявление каждого уголовно наказуемого деяния и всех их совместно взятых производить в индивидуально определенном социуме негативные изменения общественного бытия.

Более того, характеристику степени данной опасности, по нашему мнению, следует сублимировать как через характеристику обязательных признаков состава соответствующего преступления, так и через фиксацию и закрепление ряда факторов, находящих свое место явно за пределами законодательной конструкции анализируемого нами противоправного деяния.

Формальным основанием для подобного анализа при уголовно наказуемой порче земли, будет выступать, по нашему мнению, определенного рода научно правовые суждения о результатах совершения анализируемого нами общественно опасного деяния.

Так, например, намереваясь объяснить саму суть и содержание последствий любого рода преступлений Н.И. Даньшин пытался, в свою очередь, сфокусировать внимание своих возможных оппонентов на отсутствие реальной гарантии наличия социально обусловленных стандартов жизнедеятельности физических лиц и предпосылках к физической незащищенности неопределенного круга последних [3].

В настоящий момент, как напрямую свидетельствует об этом российская Государственная санитарно-эпидемиологическая служба, в нашей стране, по санитарнохимическим показателям, 12,7\% проб гумуса не отвечают гигиенически предусмотренным нормативам, а по микробиологическим, в свою очередь - 17,9\% проб.

Следовательно, около 15 \% всей территории современной Российской Федерации фактически полностью выведены из сельскохозяйственного оборота и более того экономическое и иное использование последних влечет за собой вполне реальную опасность для жизни и здоровья ее населения [https://ugkk:/uk/254:html].

Кроме того, современные российские эпидемиологи неоднократно высказывали мнение о том, что игнориро- 
вание необходимости разрешения со стороны государственных органов проблем, связанных с недопустимостью загрязнения поверхностного слоя земель отходами производства и человеческого потребления, а также и захламление земель бытовыми отходами, с определённой долей неизбежности вызовет в дальнейшем последующее загрязнение всех сред человеческого обитания, что неизбежно будет способствовать не только довольно высокой заболеваемости населения России, но и неизбежной аномальной деградации последней.

Более того, подобное изменение социального статуса земель будет также обуславливать и реальное сокращение всего объема земельных ресурсов, необходимых и достаточных для осуществления аграрной деятельности на территории всей нашей страны.

Следовательно, все перечисленные выше факторы выступают в качестве одной из причин, способствующих не только реальному сокращению народонаселения Российской Федерации, но и неизбежной зависимости от импорта отдельных видов сельскохозяйственной продукции, что в свою очередь, будет влиять негативным образом, причем как на экологическую, так и экономическую безопасность России [10].

Следовательно, наличие общей социально значимой опасности и есть именно те преступные последствия, изначально характеризующие общественную опасность порчи земли.

«...В результате совершения преступлений и наступления последствий первого порядка, - как весьма справедливо и обоснованно указывал А.И. Марцев, - в обществе происходят существенные изменения вынужденного характера, направленные на предотвращение возможной опасности от новых преступлений» [12].

Необходимо при этом особо отметить, что подобного рода опасность анализируемого нами преступления заранее не ограничивается причинением вреда социально значимым общественным отношениям. В качестве отдельных социальных последствий настоящего преступного деяния выступают также и психологические.

Так, например, уже многие современные российские экологи, явно не без основания, заявляют при этом, что продолжающее загрязнение российских земель выступает в качестве явной угрозы ее национальной безопасности [4].

Впрочем, при этом, норма современного российского уголовного законодательства предусматривающая наказание за приведение в негодность поверхностный слой земли ныне почти не применятся [14].
Создавшееся положение, безусловно, приводит к появлению у населения Российской Федерации обостренного чувства страха, что, несомненно, меняет в целом и сам психологический облик современного нам российского общества.

Таким образом, анализируемое нами преступное деяние неизбежно оказывает весьма ощутимое отрицательное морально-психологическое влияние на граждан нашей страны, порождая при этом у них вполне обоснованное беспокойство за свою жизнь и жизнь близких им людей, вселяя при этом в них чувство абсолютной незащищенности и неуверенности в завтрашнем дне. Как следствие последнего сложившейся ситуацией в своих корыстных целях пользуются наши зарубежные оппоненты, а у населения нашей страны появляется полное неверие в способность российского государства реально защитить их права, жизнь и здоровье, и обуздать при этом российскую преступность, в том числе и в сфере экологии.

К факторам, учитываемым российским законодателем при решении вопроса о необходимости криминализации такого общественно опасного деяния, как порча земли, безусловно, относится и общая характеристика современной российской преступности.

Так, например, количество выявленных и зарегистрированных в Российской Федерации преступлений по итогам девяти месяцев прошлого года выросло на $2 \%$. Об этом напрямую свидетельствуют данные Генпрокуратуры России.

Согласно которым, «...в январе - сентябре 2020 года на территории России зарегистрировано 1521683 преступления, что на 30804 больше, чем за аналогичный период прошлого года (на 2,1\%)» [UgKK.ruspriznakiprostupkov-i-prestuplenij.html].

Более того, в соответствии с отчетом Генеральной прокуратуры РФ следует, что за 11 месяцев ушедшего года в России зафиксирован рост количества преступлений на 1,2\%. Их общее число достигло отметки в 1,9 миллиона случаев, хотя в целом по регионам рост преступности идет явно неравномерно [https://genproc.gov. ru/stat/data/1798306/].

Таким образом, в 2020 году число преступлений в России выросло на 2\% по сравнению с прошлогодними показателями.

Впрочем, устанавливая уголовно-правовой запрет на совершение порчи земли, современный российский законодатель, прежде всего, обращает внимание на конкретные статистические показатели, характеризующие именно это криминализированное деяние. В связи, 
с чем М.П. Клейменов весьма справедливо, по нашему мнению, отмечает, что именно «...статистическими закономерностями подтверждена практика уголовного преследования» [8].

Так, например, в соответствии со статистическими данными представленными российской общественности ГИАЦ МВД России 1 количество зарегистрированных преступных деяний, подлежащих квалификации по ст. 254 УК РФ, составило: 1997 г. - 3; 1998 г. - 6; 1999 г. - 7; 2000 г. $-10 ; 2001$ г. - 9; 2002 г. - 13; 2003 г. - 21; 2004 г. 12; 2005 г. - 14; 2006 г. - 87; 2007 г. - 34, а с 2013 по 2015 год на территории Российской Федерации было зарегистрировано уже 12854 подобных преступлений [https:// studword.ru ], а в 219 г. - 263.

При этом с 2000 по 2004 год согласно официальным статистическим данным, в Российской Федерации правоохранительными органами не было зарегистрировано ни одно уголовное дело, возбужденное по признакам ст. 254 УК РФ, производство по которому бы окончилось в дальнейшем обвинительным приговором [http://lawtheses.com/porcha-zemli-kriminalisticheskoeobespechenie-rassledovaniya\#ixzz6jsfHsRw4].

По данной статье за период с 1997 г. по 2005 г. реально было привлечено к уголовной ответственности всего 14 человек [18].

И это по всей нашей стране с ее явно тяжелейшей экологической ситуацией.

Следовательно, весьма важным фактором, порождающим подобный уголовно-правовой запрет, является именно криминологическая характеристика анализируемого нами преступления.

При этом даже явный поверхностный анализ статистических данных, полученных нами из разных источников, в том числе и из ГИАЦ МВД России [https://мвд.рф/ reports/item/19655871/], позволяют нам сделать явно безусловный вывод о их медленном, но явном и видимо вполне очевидном росте.

\section{ЛИТЕРАТУРА}

1. Гальперин И.М. Основные направления борьбы с преступностью. М., 1975.

2. Дагель П.С. Условия установления уголовной наказуемости Правоведение. 1975. № 4.

3. Даньшин И.Н. Уголовно-правовая охрана общественного порядка. М., 1973.

4. Дубовик 0.Л. Экологическое право: Учебник. М.: Проспект, 2009.

5. Злобин Г.А. Основания и принципы уголовно - правового запрета //Сов. государство и право. 1982. № 4.

6. Ивлева А.Ф. Земельные отношения как объект уголовно-правовой охраны по законодательству Российской Федерации: теоретические и правоприменительные аспекты: диссертация ... кандидата юридических наук: 12.00.08. Нижний Новгород, 2007. 215 с.: ил. РГБ 0Д, 61 07-12/2371

7. Карпец И.И. Преступность: иллюзии и реальность. М., 1992.

8. Клейменов М.П. Уголовно - правовое прогнозирование. Томск, ТГУ, 1991.

9. Курляндский В.И. Уголовная политика: дифференциация и индивидуализация уголовной ответственности // Основные направления борьбы с преступностью. М., 1975.

10. Манакин Н.А. Уголовно правовая охрана земельных отношений в Российской Федерации. дис. ... канд. юрид. наук: 12.00.08: Н. Новгород, 2001 196 с. РГБ ОД, 61:01-12/783-9.

11. Марцев А.И. Некоторые вопросы методологии уголовно-правовых исследований // Актуальные проблемы теории уголовного права и правоприменительной практики. Красноярск, Сиб ЮИ МВД РФ, 1997.

12. Марцев А.И. Преступление как социальное явление //Актуальные проблемы борьбы с преступностью и правоприменительная практика. Красноярск, СибЮИ МВД РФ, 1998.

13. Основания уголовно- правового запрета. М., 1982.

14. Сухова Е.А. Теоретические и практические проблемы уголовной ответственности за земельные преступления // СПС "КонсультантПлюс".

15. Тоболкин П.С. Социальная обусловленность уголовно-правовых норм. Свердловск, 1983.

16. Фефелов П.А. Критерий установления уголовной наказуемости деяний // Сов. государство и право. 1970. № 11.

17. Филимонов В.Д. Криминологические основы уголовного права. Томск, ТГУ, 1981.

18. Состояние преступности в России за январь-декабрь 2005 года. - М.: Главный информационно-аналитический центр МВД РФ, 2006. - С.26; Состояние преступности в России за январь-декабрь 2006 года. - М.: Главный информационно-аналитический центр МВД России, 2007. - С. 22; Состояние преступности в России за январь-сентябрь 2007 года / http:www.mvd.ru - официальный сайт МВД России.

(c) Агафонов Александр Владимирович (info@kgau.krasedu.ru). 